\title{
Uso de Redes Neurais Artificiais para Filtragem de Ondas Sonoras Não Radiantes em Superfícies Vibrantes
}

\author{
Luís Filipe P. Perrú* ${ }^{*}$ Cleber de A. Corrêa Junior Rosilene A. Portella Corrêa \\ Depto de Ciências Exatas, Biológicas e da terra, INFES, UFF, \\ 28470-000, Santo Antônio de Pádua,RJ \\ E-mail: luis.filipe1993@hotmail.com cleberacj@id.uff.br, rosileneportella@id.uff.br
}

Roberto Aizik Tenenbaum

Programa de Pós-graduação em Modelagem Computacional, IPRJ, UERJ,

28630-050, Nova Friburgo,RJ

E-mail: ratenenbaum@gmail.com

\section{RESUMO}

Este trabalho utiliza a modelagem computacional no estudo do fenômeno da radiação acústica de superfícies vibrantes, mais especificamente a identificação de fontes sonoras, área que possui inúmeras aplicações. Dentre elas, a melhoria acústica de produtos ou equipamentos ruidosos como, por exemplo, compressores de ar, ventiladores, máquinas de lavar, dentre outros em que o ruído é um algo indesejado. Diversas indústrias, como a automobilística e de eletrodomésticos, tem investido nos últimos anos em tecnologias que deixem seus produtos mais atrativos do ponto de vista acústico.

Nesse contexto, é de fundamental importância um método que identifique as regiões de uma superfície vibrante que realmente contribuem para a potência sonora que será radiada, permitindo ao fabricante tomar as providências enquanto seu produto encontra-se na fase de testes. Uma técnica como essa existe e foi criada por [3], denominada intensidade supersônica (IS). A IS é uma grandeza que considera somente as componentes de onda que radiam para o campo distante, removendo as componentes evanescentes e que sofrem cancelamento. Através desse método tem-se o pleno conhecimento das regiões efetivamente radiantes de uma superfície vibrante. Entretanto, o método só se aplica a superfícies muito específicas, ditas superfícies separáveis.

Recentemente, um método numérico equivalente a IS foi proposto por [1], dando origem a intensidade acústica útil, ou simplesmente, intensidade útil (IU), grandeza que identifica as regiões radiantes em superfícies vibrantes de geometrias arbitrárias. O modelo proposto é mais direto do que os métodos numéricos existentes, pois é totalmente formulado na superfície vibrante, com sua formulação partindo da equação integral de Kirchoff-Helmholtz (ver [1] para maiores detalhes), dada por:

$$
c \hat{p}(X, \omega)=\int_{\Gamma}\left(i \omega \rho_{0} \hat{v}_{n}\left(X_{s}, \omega\right) G\left(X_{s} \mid X\right)-\hat{p}\left(X_{s}, \omega\right) \frac{\partial G\left(X_{s} \mid X\right)}{\partial n_{s}}\right) d \Gamma
$$

A distribuição da velocidade normal à superfície é obtida com o uso do método de elementos finitos, e depois então relacionada com a potência sonora radiada através de um operador (uma matriz) obtido com o uso do método dos elementos de contorno na Eq. (1). Tal operador, denominado de operador de potência, é Hermitiano, dessa forma, seus autovetores formam uma base ortonormal para essa distribuição de velocidade. Este fato é crucial para a obtenção da intensidade acústica útil, após a aplicação da decomposição em autovalores e autovetores no operador de potência, e do critério de

*bolsista de Iniciação Científica PIBIC/UFF 
truncamento proposto para a série desenvolvida por [1]:

$$
\Pi=\sum_{i=1}^{r} \lambda_{i}\left\langle\hat{v}_{n}^{H}, V_{i}\right\rangle\left\langle V_{i}^{H}, \hat{v}_{n}\right\rangle \approx \sum_{i=1}^{r_{c}} \lambda_{i}\left\langle\hat{v}_{n}^{H}, V_{i}\right\rangle\left\langle V_{i}^{H}, \hat{v}_{n}\right\rangle,
$$

com $r_{c} \leq r$, onde $r_{c}$ é uma quantidade suficiente, $\lambda_{i}$, de autovalores retidos (Ver [1] para maiores detalhes).

O objetivo desse estudo é produzir um critério automático que forneça o ponto de truncamento, $r_{c}$, para diferentes situações/geometrias. Para tanto, utiliza-se redes neurais artificiais (RNA), uma técnica baseada no sistema neural humano. Unidades de processamento denominadas neurônios conectados através de pesos sinápticos formam uma rede que reconhece padrões muitas vezes ocultos a percepção humana. Neste trabalho foi usado o algoritmo Backpropagation com momentum e taxa de aprendizagem adaptativa. Trata-se de um algoritmo de aprendizado supervisionado em que a rede "aprende"com os padrões que lhe são fornecidos [2], isto é, os pesos sinápticos são adaptados a partir do algoritmo proposto, normalmente fornecendo uma melhor conexão entre os neurônios a cada nova interação. Em determinado momento, os dados processados aproximam-se dos padrões de saída e a rede adquiri autonomia para realizar predições.

A RNA fornece como resultado um ponto $r_{c}$ situado na região de truncamento para superfícies vibrantes com a geometria de placa retangular. Em $100 \%$ dos ensaios numéricos realizados a RNA conseguiu indicar um $r_{c}$ adequado para a série (2), preservando, como esperado, o valor da potência sonora. Apresenta-se abaixo o resultado da obtenção da intensidade útil com o uso da RNA para o truncamento. Utilizou-se uma placa de dimensão $2 \mathrm{~m}$ por $2 \mathrm{~m}$, excitada na frequência de $533.58 \mathrm{~Hz}$. O não uso do truncamento resulta na utilização de todos os autovalores (dando origem a intensidade acústica convencional), em outras palavras, no uso de todos os pontos da malha, que nesse caso foi 961 , e com o uso do truncamento foi de apenas 31 pontos. Ambas as intensidades obtiveram uma potencia sonora de 54,6 $\mathrm{dB}$.

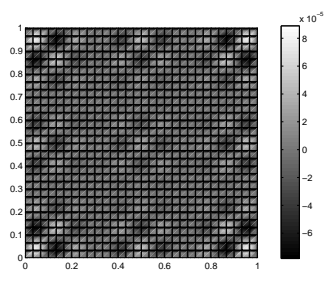

(a)

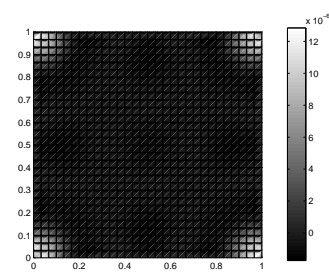

(b)

Figura 1: (a) Intensidade acústica convencional (watts $/ \mathrm{m}^{2}$ ). (b) Intensidade útil (watts $/ \mathrm{m}^{2}$ ).

Atualmente, alguns testes com a RNA são feitos para verificar sua precisão em predizer o ponto de truncamento para uma superfície em forma de um cilindro com tampas, geometria não tratada pelo método desenvolvido por Williams. Posteriormente, o objetivo é testá-la em uma superfície mais complexa e realística como, por exemplo, um compressor.

Palavras-chave: Intensidade Útil, Intensidade Supersônica, Acústica, Redes Neurais Artificiais

\section{Referências}

[1] C.A. Corrêa Junior, R.A. Tenenbaum, "Useful intensity: A technique to identify radiating regions on arbitrarily shaped surfaces". Journal of Sound and Vibration, 332, 1567-1584, 2013.

[2] S. Haykin, ”Redes Neurais - Princípios e práticas", Bookman, Brasil, 2000.

[3] E.G. Williams, "Supersonic Acoustic Intensity", Journal of the Acoustical Society of America, 97, 121-127, 1995. 